\title{
Article \\ A Proposal for a Simple Method for Determining the Concrete Slab Width of Composite Beam-to-Column Joints
}

\author{
Linfeng Lu ${ }^{1, * \mathbb{D}}$, Di Wang ${ }^{2}$, Kai Ding ${ }^{1}$, Hongwei Yan ${ }^{1}$ and Hanlin Hao ${ }^{1}$ \\ 1 School of Civil Engineering, Chang'an University, 75 Chang'an Middle Rd, Xi'an 710062, China; \\ 2019128008@chd.edu.cn (K.D.); 2020128014@chd.edu.cn (H.Y.); 2021128031@chd.edu.cn (H.H.) \\ 2 China Construction Third Bureau Group Co., Ltd., Mai Hua Rd., Nanjing 210004, China; wangdi@cscec.com \\ * Correspondence: lulinfeng@chd.edu.cn
}

Citation: Lu, L.; Wang, D.; Ding, K.; Yan, H.; Hao, H. A Proposal for a Simple Method for Determining the Concrete Slab Width of Composite Beam-to-Column Joints. Appl. Sci. 2021, 11, 9613. https://doi.org/ 10.3390/app11209613

Academic Editor: Doo-Yeol Yoo

Received: 27 September 2021

Accepted: 13 October 2021

Published: 15 October 2021

Publisher's Note: MDPI stays neutral with regard to jurisdictional claims in published maps and institutional affiliations.

Copyright: (c) 2021 by the authors. Licensee MDPI, Basel, Switzerland. This article is an open access article distributed under the terms and conditions of the Creative Commons Attribution (CC BY) license (https:// creativecommons.org/licenses/by/ $4.0 /)$.
Abstract: Extensive brittle failures in the weld zone of the beam bottom flange in composite joints of SMRFs were observed during the Northridge earthquake and the Kobe earthquake. One of the main reasons is the large tensile strain demand generated at the beam bottom flange zone under positive bending. The key to accurately understanding the mechanical properties of composite joints is the effective width of the slab. However, researchers have no consensus on the flange slab's effective width for composite joints, even with the simplest solid concrete slab. Therefore, the best way to design the composite joint specimen is by following the current design specifications. However, each specification implements different ideas and approaches for specifying an effective slab width. This paper presents comparisons of the effective flange width provisions in China, the United States, Australia/New Zealand, and the European Union. The characteristics of each provision are briefly described and summarized. Numerical comparisons for positive and negative moment regions of continuous spans follow. Based on the commonalities and main differences among all these provisions, we propose a recommended equation for calculating the effective width of a solid concrete slab, reflecting the specification differences. The reliability of the recommended equation was verified with ABAQUS software analysis. The recommended equation can meet the fast and secure design requirements for composite joints in tests with concrete slabs.

Keywords: joints; composite; effective flange width; specifications; SMRFs

\section{Introduction}

During the Northridge earthquake in1994 and the Kobe earthquake in 1995, many steel moment-resisting frames (SMRFs) suffered fractures in welded moment connections. Typical failure modes of the welded moment connections are shown in Figure 1. The buildings could not be repaired nor continue to be used because of the brittle failure of the joints after the earthquakes [1-3]. One of the reasons is the effect of the concrete slab, which causes the neutral axis to move toward the top flange when subjected to positive beam bending (concrete slab under compression) and the strain on the bottom flange to be much larger than that of the top flange. This strain concentration on the bottom flange may lead to premature failure of the connection. An illustration of a composite beam-to-column connection subjected to a seismic load is shown in Figure 2 [4]. There are three parts in a combined joint - the steel beam or girder, the slab, and the shear connector between a steel beam and slab. Sometimes, the shear connectors and slab strongly influence the mechanical properties of composite beam-to-column joints. Regarding shear connectors, their effects have been investigated [5,6]. In addition, some authors [4,7-11] have studied the slab influence on composite joints. 


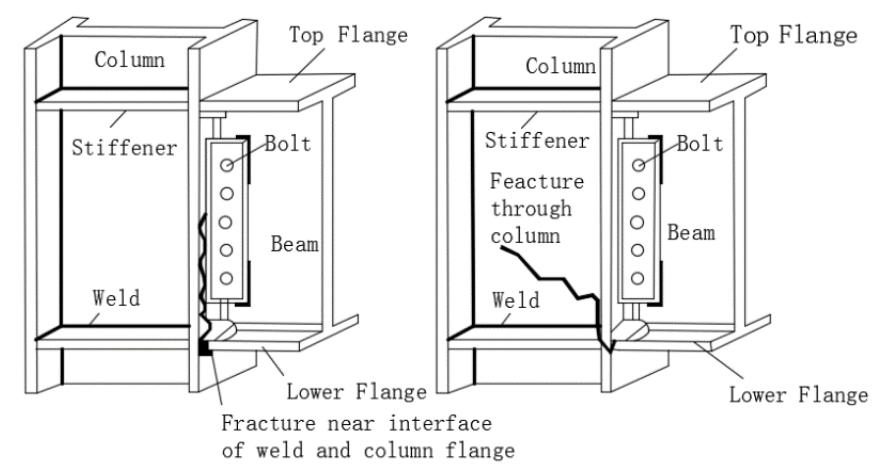

Figure 1. The brittle failure of a rigid connection in the Northridge earthquake.

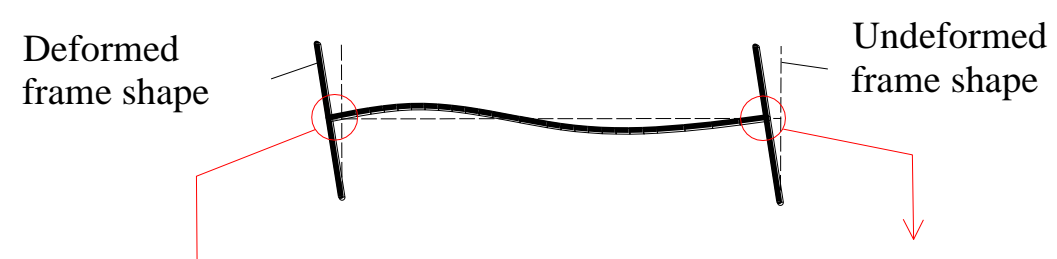

Behavior of Steel Frames

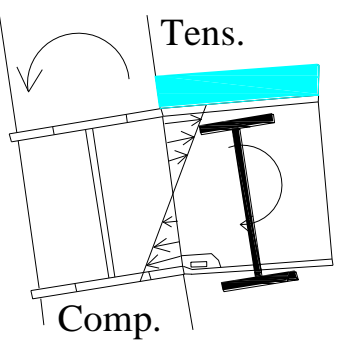

Negative Bending

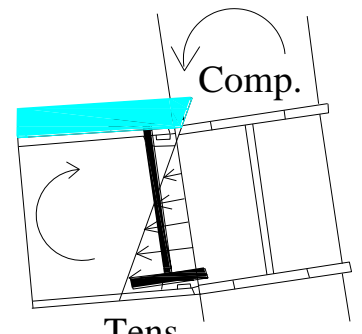

Tens.

Positive Bending

Figure 2. Strain distributions of composite beams.

However, the key to accurately understanding the mechanical properties of composite joints is the effective width of the slab, including reinforced concrete slab or composite slab, because the effective width of the concrete slab is the essential part of a composite joint in the experiments mentioned above. Of course, it is also the key to the correct design of the composite joint. The design provision is the rule or the law when a structural engineer designs the SMRFs involved in the composite joint. Many countries and associations had design provisions in their design specifications or standards to calculate the effective flange slab width in the hogging moment and sagging moment regions for composite beams. However, for composite joints, only EN 1994-1-1:2004 [12] and AS/NZS 2327:2017 [13] gave the design provision for a special semi-rigid bolted endplate composite joint. In other design specifications, there are no design provisions for the composite joint. In the SMRFs design, the assumption of the connection between the column and beam is always a rigid connection; the mechanical behaviors of the composite joint are similar to continuous spans of a composite beam under a gravity load. Because the bending moments at the beam end of the composite joint are alternately positive and negative under the cyclic action of earthquakes, in order to check whether the provisions of current design provisions on the effective flange width of composite beams under the act of positive and negative bending moments are suitable for composite joints, in this study, we compared the effective flange width provisions of China, the United States, Australia/New Zealand, and the European Union, and compared them with the current research results of composite joints. Finally, the design recommendations for the slab width of composite joint specimens are given. 


\section{Shear Lag and Effective Flange Width of a Composite Beam}

Our research found that the shear strains in the concrete flange of a composite beam do not allow for the cross-sections to remain plane, leading to a non-uniform normal stress distribution along the slab width. This phenomenon was named the shear lag effect $[14,15]$. Thus, De Saint Venant's theory cannot be used for studying the composite beam. Instead, by replacing the acting flange width with an appropriately reduced, uniformly stressed effective flange width, shear lag effects can be accounted for. Therefore, the elementary beam bending theory can be used. Nowadays, to consider the shear lag effect and avoid complex evaluations, utilizing the effective width of the RC slab or composite slab with profiled steel sheeting to evaluate the combined effect of the slab is a standard method in scientific research or practical project design. Using effective flange width of a concrete slab to do global structural analysis is mainly concentrated in the three engineering fields of civil engineering, reinforced concrete structural buildings [16] and reinforced concrete bridges [17], steel bridge and composite steel bridge [18], and steel structural building [19] and composite steel structural building [20].

Graphically, the three-dimensionally changing normal stress at a distance $x, \sigma_{x}=\sigma_{x}(y, z)$ is represented by its maximum value, shown as $\sigma_{x, \max }$ in Figure 3 . The force effects on the flange are required to be the same for both cases, as shown in Figure 3. The relationship is expressed as Equation (1), where $b_{\mathrm{e}}$ is the one-side effective flange width of the composite beam, $2 b$ is the beam spacing or slab span, $t$ is the thickness of the slab, and $\sigma_{x}$ is the normal stress in the $x$-direction. As illustrated in Equation (1) and Figure $3, b_{\mathrm{e}}$ is a function of $x$ and the stress distribution changes with loading conditions. Because the variations (the geometry parameters, loading conditions, etc.) strongly affect the effective flange width, design specifications seek to incorporate simple rules that can deliver appropriate values of effective flange width and apply a different philosophy of simplification. Thus, the other compromise between accuracy and simplicity can be seen in the following sections with compared results.

$$
b_{\mathrm{e}}=\frac{\int_{-t / 2}^{t / 2} \int_{0}^{b} \sigma_{x}(y, z) \mathrm{d} y \mathrm{~d} z}{t \cdot \sigma_{x, \max }(y, z)}
$$

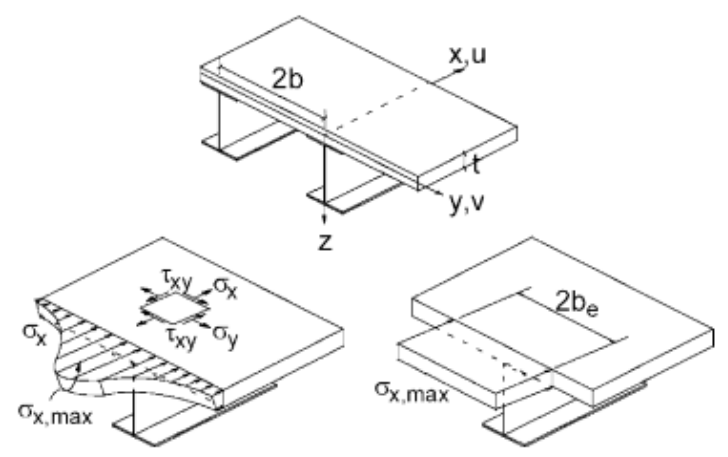

Figure 3. Concept of effective flange width [18].

\section{Provisions for Effective Flange Width of the Composite Beam in Current Design Specifications}

Some previous researchers have compared the similarities and differences among the design provisions of different countries or regions [21-23]. However, the comparisons made are between bridge specifications and building codes. Parts of those codes or specifications have either been abolished or superseded. Therefore, this article only lists some of the current design specification provisions that the authors have collected. The composite beam end of a composite joint of the steel moment resistance frame usually bears negative bending under the gravity loading. Still, under seismic action, the bending moment may be positive or negative. Thus, design provisions of the effective width of a concrete slab under positive bending moment and negative bending moment are listed in Sections 3.1-3.4, following the latest version that the author can collect. 


\subsection{EN 1994-1-1:2004}

EN 1994 is the Structural Eurocode that deals with composite steel and concrete structures. Among others, it replaced the following national standards: BS 5400-5, BS 5950-3.1, and BS 5950-4. EN 1994 also replaced the national standards in many other countries, not only in the United Kingdom. EN 1994 consists of three parts: Part 1-1, General rules and rules for buildings (EN 1994-1-1); Part 1-2, General rules-Structural fire design (EN 1994-1-2); Part 2, General laws and rules for bridges (EN 1994-2).

EN 1994-1-1:2004 incorporated corrigendum in April 2009. It is the oldest version of the current specification, but it significantly impacts design specifications in many countries, including the United States, Australia, New Zealand, and China. According to EN 1994-1-1:2004 [12], “Action effects may be calculated by global elastic analysis, even where the resistance of a cross-section is based on its plastic or non-linear resistance", "The effects of shear lag and local buckling shall be taken into account if these significantly influence the global analysis", and "Allowance shall be made for the flexibility of steel or concrete flanges affected by shear in their plane (shear lag) either by means of rigorous analysis or by using an effective width of the flange." The following provisions should determine the effective width of concrete flanges.

(a) When the global elastic analysis is used, a constant effective width may be assumed over the whole of each span. This value may be taken as the value $b_{\text {eff, } 1}$ at mid-span for a span supported at both ends, or the value $b_{\mathrm{eff}, 2}$ at the support for a cantilever.

(b) At mid-span or internal support, the total effective width $b_{\text {eff }}$, see Figure 4 , may be determined by the following equation:

$$
b_{\text {eff }}=b_{0}+\sum b_{\text {ei }}
$$

where

$b_{0}$ is the distance between the centers of the outstand shear connectors;

$b_{\mathrm{ei}}$ is the value of the effective width of the concrete flange on each side of the web and taken as $L_{\mathrm{e}} / 8$ but not greater than the geometric width $b_{\mathrm{i}}$. The value $b_{\mathrm{i}}$ should be taken as the distance from the outstand shear connector to a point mid-way between adjacent webs, measured at mid-depth of the concrete flange. Except at a free edge, $b_{\mathrm{i}}$ is the distance to the free edge. The length $L_{\mathrm{e}}$ should be taken as the approximate distance between points of zero bending moment. For typical continuous composite beams where a moment envelope from various load arrangements governs the design, and for cantilevers, $L_{\mathrm{e}}$ may be assumed to be as shown in Figure 4.

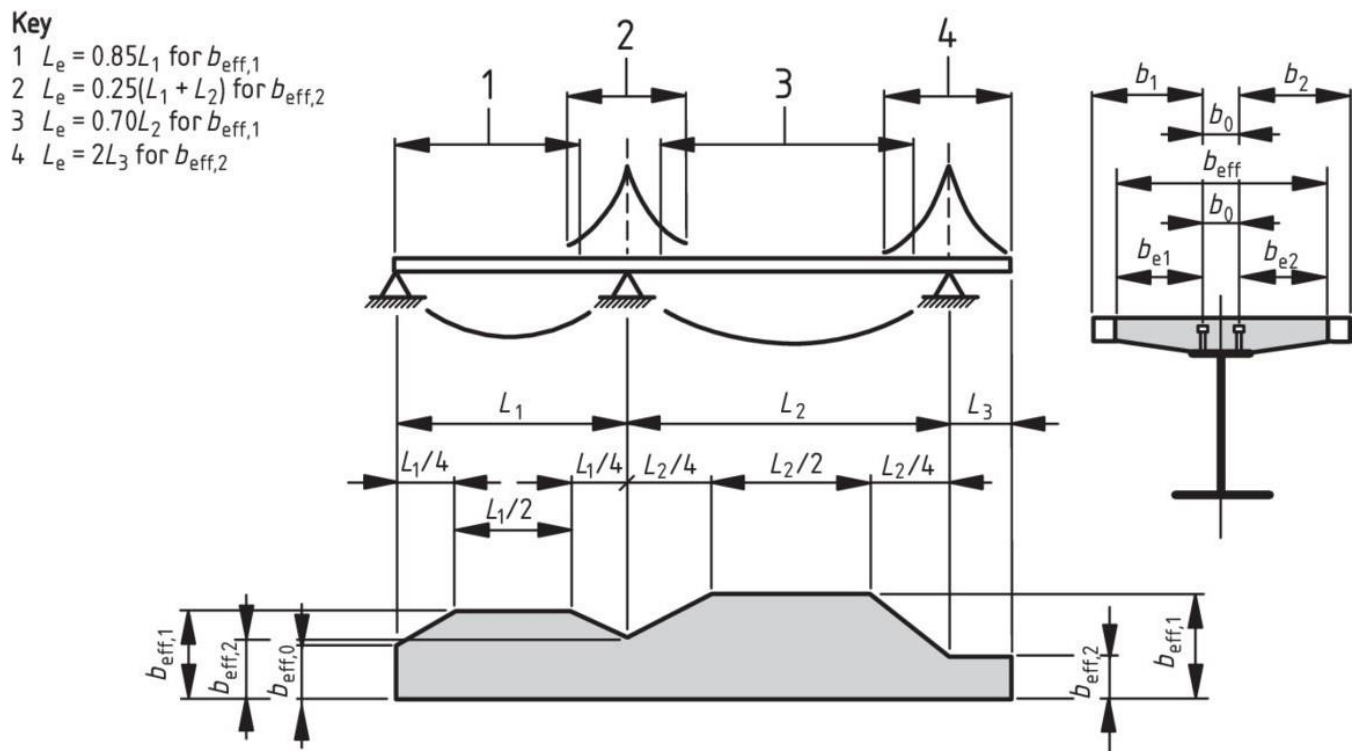

Figure 4. Equivalent spans for the effective width of the concrete flange in EN 1994-1-1 [12]. 
(c) The effective width at end support may be determined by the following equation:

$$
b_{\mathrm{eff}}=b_{0}+\sum \beta_{\mathrm{i}} b_{\mathrm{ei}}
$$

with

$$
\beta_{\mathrm{i}}=\left(0.55+0.025 L_{\mathrm{e}} / b_{\mathrm{ei}}\right) \leq 1.0
$$

where

$b_{\mathrm{ei}}$ is the effective width (see (b)) of the end span at mid-span, and $L_{\mathrm{e}}$ is the equivalent span of the end span, according to Figure 4.

(d) The distribution of the effective width between supports and mid-span regions may be assumed to be as shown in Figure 4.

(e) Where the bending moment distribution is influenced by the resistance or the rotational stiffness of a joint in buildings should be considered in the determination of the length $L_{\mathrm{e}}$.

(f) For analysis of building structures, $b_{0}$ may be taken as zero and measured from the center of the web.

In EN 1994-1-1:2004, for serviceability limit states, the elastic analysis should be used with appropriate corrections for non-linear effects such as the cracking of concrete. Therefore, when the elastic analysis is used, the effective width at the ultimate limit state is taken as a constant value for the middle portion of the span and tapers towards the points of zero moments, as shown in Figure 4. In addition, when multiple shear connectors are provided, the effective width may be increased by the distance between the outermost shear connectors measured from their centerlines, $b_{0}$ (see Figure 4 ). However, for the serviceability limit state, the EN 1994-1-1 provisions are similar to those of BS 5950-3.1, in that a constant effective breadth may be assumed to act over the entire span, based on the mid-span value.

In EN 1994-1-1, the maximum value of the effective width $b_{\mathrm{e} 1}=b_{\mathrm{e} 2}=\mathrm{span} / 8$ is on each side of the beam (see Figure 4). As well as considering this limit, the width assumed in the design must not exceed the actual slab width available, which is particularly relevant to edge beams and beams adjacent to openings. The rules of EN 1994-1-1 are more generous when the slab spans parallel to the span of the beam.

\subsection{AS/NZS 2327:2017}

As previously stated, EN 1994-1-1 has a significant impact on the design specifications of Australia and New Zealand. Still, AS/NZS 2327:2017 [13] has made greater progress towards perfection than EN 1994-1-1 because, in AS/NZS 2327:2017 clause 3.4.2, provisions of the effective width of concrete flange have three parts according to the type of slab. The first part is clause 3.4.2.1 for the solid slab, the second part is clause 3.4.2.2 for the composite slab, and the third part is clause 3.4.2.3 for the void slab. In clause 3.4.2.1, for the solid slab, the provisions of effective width are the same as in EN 1994-1-1 and use the same diagram as in Figure 4 to clarify the equivalent width. Still, it has a unique requirement-when a slab has pockets or a cut-out within its effective width, then, at the cross-section of concern, the effective width shall be reduced by the width they encroach into this region. In clause 3.4.2.2, for a composite slab in which the ribs are parallel to or within $15^{\circ}$ of the steel beam axis, the effective width of the concrete flange shall be calculated by clause 3.4.2. For a composite slab in which the ribs form an angle greater than $15^{\circ}$ from the axis of the steel beam, only the contribution of the concrete above the ribs shall be considered based on the effective width calculated by clause 3.4.2.1. In clause 3.4.2.3, where the concrete flange consists of the avoided slab, the effective width is reduced to account for the loss in compression transfer, which occurs as a consequence of the voided slab units. However, the effective width determined by Equation (5) cannot exceed that 
determined by clause 3.4.2.1. Voided slab depths shall not exceed $260 \mathrm{~mm}$, and the plastic neutral axis of the cross-section shall lie in the steel beam.

$$
b_{\text {eff }}=\left(\frac{\sqrt{1.2 f_{c}^{\prime}}}{40} \frac{32 d_{b}}{500} \frac{f_{s y}}{460} 100\right)+2.5 g
$$

where

$f_{\mathrm{c}}{ }^{\prime}$ is the characteristic compressive (cylinder) strength of concrete at 28 days, $d_{\mathrm{b}}$ is the diameter of the transverse reinforcement, $f_{\text {sy }}$ is the characteristic strength of the reinforcement, and $g$ is the gap between the ends of the precast units.

\subsection{GB50017-2017}

EN 1994-1-1 also dramatically impacts the design specification GB50017-2017 [24] of China, but GB50017-2017 has made greater progress towards perfection than EN 1994-1-1. In GB50017-2017, slabs are still divided into three categories, the first is the solid slab, the second is the laminated concrete slab, and the last is the composite slab. Unlike AS/NZS 2327:2017, there is no difference in the effective width of the above three types of slabs. Therefore, more detailed research may be required, especially for the laminated concrete slab. The effective width $b_{\mathrm{e}}$ of the concrete slab at the mid-span and intermediate supports when performing the load-bearing capacity check of the composite beam section (Figure 5) shall be calculated as follows:

$$
b_{\mathrm{e}}=b_{0}+b_{1}+b_{2}
$$

where

$b_{0}$ is the width of the top of the bracket supporting. When the pallet inclination angle $\alpha$ is lower than $45^{\circ}$, it should be calculated as $\alpha$ equals $45^{\circ}$ (Figure $5 b$ ). When there is no bracket supporting, then $b_{0}$ takes the width of the top flange of the steel beam. When the concrete slab and the steel beam are not directly in contact (there is a deck sheeting between them), $b_{0}$ takes the lateral space of the studs. When there is only one column of studs, $b_{0}$ equals zero.

$b_{1}$ and $b_{2}$ are the calculated width of the outer and inner wings of the beam (see Figure 5). Therefore, when the plastic neutral axis is located in the concrete slab, $b_{1}$ and $b_{2}$ are taken as $L_{\mathrm{e}} / 6$. Additionally, $b_{1}$ should not exceed the actual overhang width $S_{1}$, and $b_{2}$ should not exceed one-half the net distance $S_{0}$ to the edge of the flange or the bracket of the adjacent beam (Figure 5).

$L_{\mathrm{e}}$ is the equivalent span. For a simply-supported composite beam, $L_{\mathrm{e}}$ takes the span of the simply-supported composite beam. For continuous composite beams, in the intermediate span and positive bending region, $L_{\mathrm{e}}$ is taken as $0.6 \mathrm{~L}$. In the side span and positive bending area, $L_{\mathrm{e}}$ is taken as $0.8 \mathrm{~L}$, where $L$ is the span of the composite beam. Finally, in the negative bending region, $L_{\mathrm{e}}$ is taken as 0.2 times the sum of the adjacent spans.

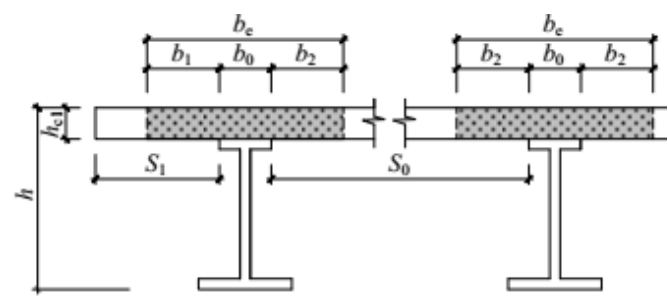

(a)

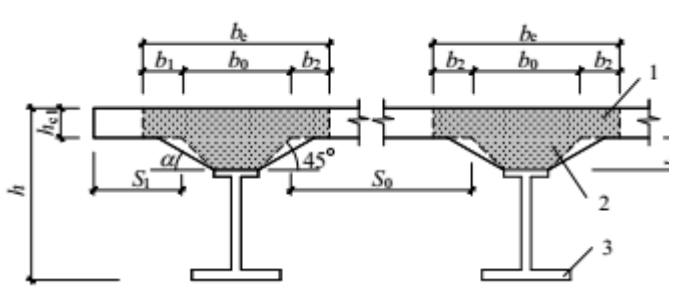

(b)

Figure 5. The effective width of a concrete flange in GB50017-2017 [24]. (a) Composite beam without bracket; (b) composite beam with bracket.

\subsection{ANSI/AISC 360-16}

In the commentary of ANSI/AISC 341-16 [25], the effective width of the slab can be determined following Chapter H of ANSI/AISC 360-16. However, through checking the 
content of the ANSI/AISC 360-16, it is found that for the version before 2018, ANSI/AISC 341-16 is correct according to Chapter H of ANSI/AISC 360-16, but for the revised versions of 2018 and 2019, Chapter I is correct.

In the design standard of ANSI/AISC 360-16 [26] revised by the American Institute of Steel Construction in 2019, the effective width of the concrete slab shall be the sum of the effective widths for each side of the beam centerline, each of which shall not exceed the following:

(a) one-eighth of the beam span, center-to-center of the supports;

(b) one-half the distance to the centerline of the adjacent beam; or

(c) the distance to the edge of the slab.

The design provisions mentioned above have never changed from AISC-LRFD [27] to ANSI/AISC 360-16 [26].

\section{Comparison of Design Specification Provisions}

\subsection{Comparison of Basic Provisions}

As previously stated, EN 1994-1-1 assumes these equations for the effective width in both elastic and plastic analyses. The comparison between the experiments and the EN 19941-1 formulation demonstrates that EN 1994-1-1 is adequate for the elastic analysis, whereas it may be too restrictive for the plastic analysis [28]. In general, AS/NZS 2327:2017 [13] covered more slab types than EN 1994-1-1:2004 [12], especially composite slabs for a wide range of applications and voided slabs suitable for prefabrication. Compared to EN 1994-1-1:2004, it can be seen that the provisions of GB50017-2017 [24] are similar to EN 1994-1-1:2004, and the parameters are more conservative than EN 1994-1-1:2004 [12]. However, ANSI/AISC 360-16 [26] does not consider the difference in the slab's effective width in the hogging and sagging bending region. Based on the descriptions in Section 3 , the characteristics of each provision are summarized and compared in Table 1.

Table 1. Comparison of provisions.

\begin{tabular}{|c|c|c|c|c|}
\hline$b_{\mathrm{e}}$ Provisions & EN 1994-1-1 & AS/NZS 2327 & GB50017 & ANSI/AISC 360 \\
\hline Expressed as one-sided & $\mathrm{Y}$ & Y & $\mathrm{N}$ & Y \\
\hline $\begin{array}{l}\text { Distinguishes exterior vs. } \\
\text { interior beam }\end{array}$ & $\mathrm{N}$ & $\mathrm{N}$ & $\mathrm{Y}$ & $\mathrm{N}$ \\
\hline $\begin{array}{l}\text { Distinguishes } \mathrm{M}(+) \text { region } \\
\text { from } \mathrm{M}(-) \text { region }\end{array}$ & Y & $\mathrm{Y}$ & $\mathrm{Y}$ & $\mathrm{N}$ \\
\hline $\begin{array}{l}\text { Distinguishes I girder from the } \\
\text { other beam }\end{array}$ & $\mathrm{N}$ & $\mathrm{Y}$ & $\mathrm{N}$ & $\mathrm{N}$ \\
\hline $\begin{array}{l}\text { Distinguishes strength } \\
\text { (ultimate) vs. service }\end{array}$ & $\mathrm{Y}$ & Y & $\mathrm{Y}$ & $\mathrm{N}$ \\
\hline Considers the type of slab & $\mathrm{N}$ & Y & $\mathrm{N}$ & $\mathrm{N}$ \\
\hline $\begin{array}{l}\text { Considers the opening or } \\
\text { cut-out of the slab }\end{array}$ & Y & $\mathrm{Y}$ & $\mathrm{N}$ & $\mathrm{N}$ \\
\hline Uses equivalent beam span & Y & Y & $\mathrm{Y}$ & $\mathrm{N}$ \\
\hline $\begin{array}{l}\text { Value modified for concrete } \\
\text { cracking }\end{array}$ & $\mathrm{Y}$ & $\mathrm{Y}$ & $\mathrm{N}$ & $\mathrm{N}$ \\
\hline
\end{tabular}

\subsection{Comparison of the Equivalent Span of Continuous Composite Beams}

Generally, sagging moment regions and hogging moment regions are considered independently in design specifications. Therefore, the entire length of a composite beam divides into exterior spans, interior spans, and internal support spans. It assumes that an exterior span or an interior span can be treated as a separate simply-supported span. The equivalent span concept is applied, and the distance between moment inflection points is 
used to determine each equivalent span. It can be seen that the most critical factor is the beam span or the equivalent beam span when using the design provisions to calculate the effective width of the slab in the four design specifications shown above. For this study, the research object was the rigid composite joint of steel moment-resisting frames (SMRFs). The mechanical properties of the fixed connection frame beam are similar to the continuous span composite beams described in the four design specifications mentioned above.

Figure 6 shows definitions of the "equivalent span" in the EN 1994-1-1, AS/NZS 2327, GB50017, and ANSI/AISC 360 provisions. Because ANSI/AISC 360 does not use the "equivalent span" concept and only uses the beam span, all the equivalent span length ratios are equal to 1.0 in Figure 6. It can be seen from Figure 6 that for exterior spans, EN 1994-1-1 and AS/NZS 2327 using 85\% of the beam span length as the effective span length, whereas GB50017 uses 80\% of it. Like the exterior span, GB50017 uses 20\% of the sum of the two adjacent beam span lengths for internal supports, whereas EN 1994-1-1 and AS/NZS 2327 using 25\%. EN 1994-1-1 and AS/NZS 2327 using 70\% of the beam span length for interior spans, and GB50017 uses $60 \%$ of the beam span length. We believe that the main reason for this difference is that the seismic design of the Chinese frame complies with strong joints and weak members. Therefore, reinforced joints are generally used for beam-column connections, and joint rotational stiffness tends to be substantial. However, European and Australian codes generally consider semi-rigid connections. Furthermore, effective span lengths equal the full continuous beam length $(L 1+L 2+L 3)$ for GB50017. For the other two provisions, EN 1994-1-1 and AS/NZS 2327, the sum of the effective beam span lengths is longer than the total continuous beam length $(L 1+L 2+L 3)$ because of using the distance between inflection points under uniformly distributed loads [18]. For example, the column distances of a steel moment resistance frame in the same direction are generally equal, and the spans of the beams are also the same. This means that beam span $L 1$ equals $L 2$ as well as $L 3$, so that the sum of the effective beam span lengths is $10 \%$ more than the total continuous beam length.

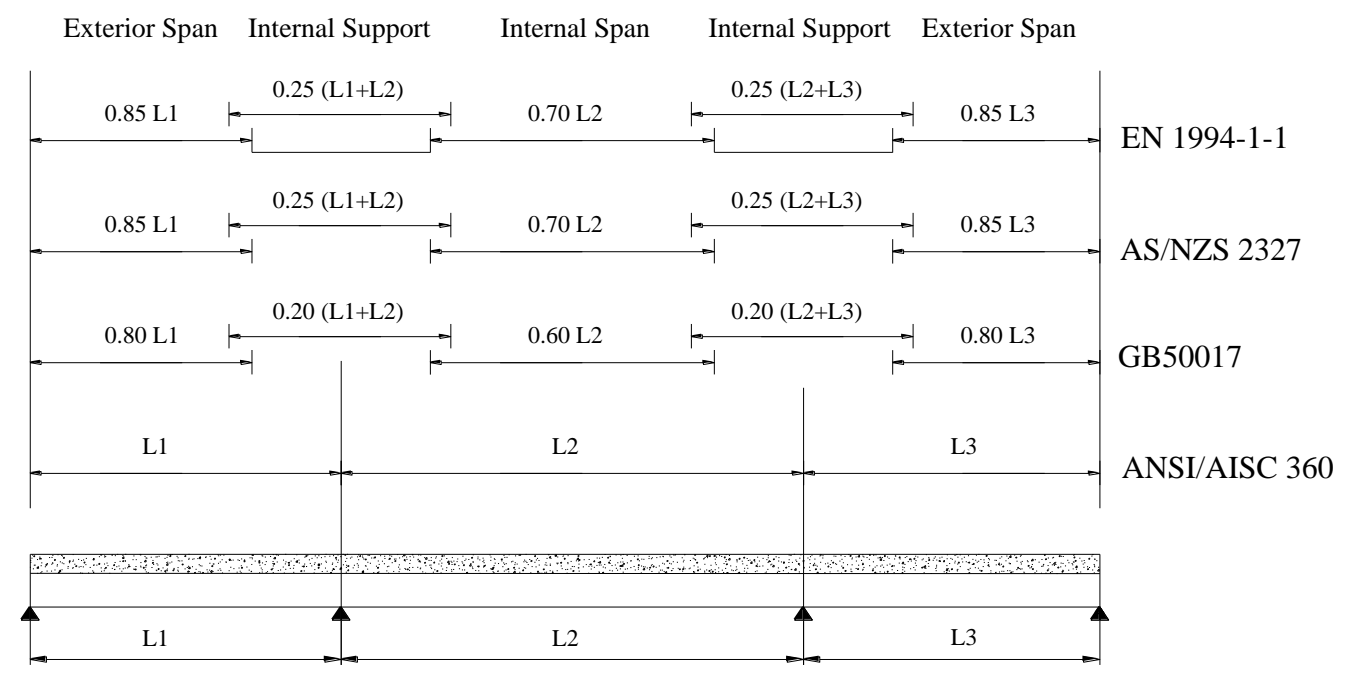

Figure 6. Equivalent span length ratios.

\subsection{Numerical Comparison of Provisions at the Positive and Negative Bending Moment Region}

The effective flange widths of continuous spans are calculated based on "equivalent spans" and "basic provisions", as discussed. In this section, the numerical values of the effective flange width are compared. Effective flange widths are calculated at the internal support regions of three-span continuous frames with the same exterior spans and solid concrete slab. The first calculation background and conditions are that the beam end span equals its mid-span, and the actual width of the concrete slab, $2 b$ of EN 1994-1-1 and AS/NZS 2327, $S_{0}$ of GB50017, will change the ratio of $S_{0}$ to beam span $L$ (column distance) from 1 to $1 / 6$. The second calculation background and conditions are that the beam end 
span $L 1$ equals 1.5 times mid-span $L$ ( $L 2$ is in Figure 6), and it changes the ratio of $S_{0}$ to $L$ from 1 to $1 / 6$. For example, the range of the regular column space or the beam span of SMRFs is about $7.5 \mathrm{~m} \sim 12 \mathrm{~m}$, and the scope of the usual supporting span of a solid concrete slab is about $1.8 \mathrm{~m} \sim 6 \mathrm{~m}$, so the ratio of $1 \sim 1 / 6$ can cover them. Regarding $b_{0}$, this is the distance between the centers of the shear connectors (Figure 4 ), and in this paper, we made $b_{0}$ equal to the value of $0.01 L$, where $L$ is the beam mid-span. According to the regular column space or the beam span of SMRFs, $L$ is about $7.5 \mathrm{~m} \sim 12 \mathrm{~m}$, and the value range of $b_{0}$ is $75 \mathrm{~mm} 120 \mathrm{~mm}$, which can cover the common distance of the shear connector in practical engineering structures. The value of $b_{0}$ of EN 1994-1-1 is somehow different from that of GB50017, but the difference is slight.

The resulting $b_{\mathrm{e}}$ and $L$ in the positive bending moment zone are listed in Table 2; the negative bending moment zone values are listed in Table 3 . It can be seen in Table 2 that although the equivalent span length of the end support is greater than the mid-span when $L 1=L 2=L 3$, the effective width $b_{\mathrm{e}}$ of the end support is less than the mid-span in Eurocode 4 and AS/NZS 2327, and the reduction is between $8 \%$ and 18\%. GB50017 is just the opposite, and improvement ranges from 0 to $32 \%$; the two values are the same for AISC360. The reason for this is that EN 1994-1-1 and AS/NZS 2327 consider reducing the effective width at the end of the span and use a modification factor $\beta i$, Equation (3), which is applied to the one-side effective width at the end supports. However, GB50017 does not consider the reduction of the effective width at the end supports, and AISC 360 does not consider the difference in the slab's effective width at the end supports and mid-span. Moreover, the equivalent span length ratios of GB50017 are less than those of EN 1994-1-1 (shown in Figure 6). Still, both effective slab widths of GB50017 at the end supports and mid-span are larger than EN 1994-1-1 in Table 2, except $S_{0} / L=1 / 6$. Among them, the maximum increase for the mid-span is $14 \%$, and the top growth for the end support is $64 \%$. The main reasons for the above differences are the effective width of the concrete flange on each side is taken as $L_{\mathrm{e}} / 8$ in EN 1994-1-1 and AS/NZS 2327, and is taken as $L_{\mathrm{e}} / 6$ in GB50017, where $L_{\mathrm{e}}$ is the equivalent span according to Figures 4 and 6 . When $S_{0} / L$ takes a value between $1 / 6$ and 1/3, both effective slab widths of AISC 360 at the end supports and mid-span is smaller than EN 1994-1-1 and GB50017. Compared with EC4, the maximum drop for the mid-span AISC360 is 53\%, and the maximum reduction for the end support AISC 360 is $42 \%$. It can be seen in Table 3 that the variation rule of the effective width of the slab in the negative bending moment region considered is basically the same as the positive moment region in Table 2, and the reason is the same as well. When the three-span continuous beams shown in Figure 6 have the same and different spans, the effective slab widths of GB50017 are about 6\% larger than those of EN 1994-1-1 and AS/NZS 2327. It is a little bit different when the value of $S_{0} / L$ is greater than $1 / 3$; the effective width of AISC 360 in the negative bending moment region is greater than that in both EN 1994-1-1 and GB50017. When the three-span continuous beams shown in Figure 6 have the same end span, the effective slab widths of AISC 360 are about $40 \%$ to $75 \%$ larger than those of GB50017. Similarly, when the spans are different (Table 3), this value is about 13\% to $111 \%$. Moreover, the effective width of the solid slab in the positive moment region calculated by other specifications-except the AISC 360-is always greater than that of the slab in the negative moment region. 
Table 2. The values of $\mathrm{b}_{\mathrm{e}}$ and $\mathrm{L}$ in the positive bending moment region considering $b_{0}=0.01 \mathrm{~L}$.

\begin{tabular}{|c|c|c|c|c|c|c|c|c|c|c|}
\hline \multirow{2}{*}{\multicolumn{2}{|c|}{ Specification }} & \multicolumn{9}{|c|}{$S_{0} / L$} \\
\hline & & 1 & $3 / 4$ & $2 / 3$ & $1 / 2$ & $1 / 2.5$ & $1 / 3$ & $1 / 4$ & $1 / 5$ & $1 / 6$ \\
\hline \multirow{2}{*}{$\begin{array}{c}\text { EN1994-1-1 } \\
\text { AS/NZS } 2327\end{array}$} & Mid-span & 0.185 & 0.185 & 0.185 & 0.185 & 0.185 & 0.185 & 0.185 & 0.185 & 0.177 \\
\hline & End support & 0.169 & 0.169 & 0.169 & 0.169 & 0.169 & 0.169 & 0.169 & 0.163 & 0.144 \\
\hline \multirow{2}{*}{ GB50017 } & Mid-span & 0.21 & 0.21 & 0.21 & 0.21 & 0.21 & 0.21 & 0.21 & 0.21 & 0.177 \\
\hline & End support & 0.277 & 0.277 & 0.277 & 0.277 & 0.277 & 0.277 & 0.26 & 0.21 & 0.177 \\
\hline \multirow{2}{*}{ AISC360 } & Mid-span & 0.25 & 0.25 & 0.25 & 0.25 & 0.2 & 0.167 & 0.125 & 0.1 & 0.083 \\
\hline & End support & 0.25 & 0.25 & 0.25 & 0.25 & 0.2 & 0.167 & 0.125 & 0.1 & 0.083 \\
\hline
\end{tabular}

Note: $b_{\mathrm{e}}$ is the effective width of the solid concrete slab, and for EN 1994-1-1, it is $b_{\mathrm{eff}} S_{0}$ is the solid concrete slab's actual width and equals the distance to the centerline of the adjacent beam; $L$ is the beam span, center to center of supports, and $L 1=L 2=L 3=L$ in Figure $6 . b_{0}$ is the distance between the centers of the outstand shear connectors.

Table 3. The values of $b_{e}$ and $L$ in the negative bending moment region considering $b_{0}=0.01 L$.

\begin{tabular}{|c|c|c|c|c|c|c|c|c|c|c|}
\hline \multirow{2}{*}{\multicolumn{2}{|c|}{ Specification }} & \multicolumn{9}{|c|}{$S_{0} / L$} \\
\hline & & 1 & $3 / 4$ & $2 / 3$ & $1 / 2$ & $1 / 2.5$ & $1 / 3$ & $1 / 4$ & $1 / 5$ & $1 / 6$ \\
\hline \multirow{2}{*}{$\begin{array}{c}\text { EN1994-1-1 } \\
\text { AS/NZS } 2327\end{array}$} & $\begin{array}{c}L 1=L 3=L 2 \\
=L\end{array}$ & 0.135 & 0.135 & 0.135 & 0.135 & 0.135 & 0.135 & 0.135 & 0.135 & 0.135 \\
\hline & $\begin{array}{c}L 1=L 3= \\
1.5 L 2=1.5 L\end{array}$ & 0.166 & 0.166 & 0.166 & 0.166 & 0.166 & 0.166 & 0.166 & 0.166 & 0.166 \\
\hline \multirow{2}{*}{ GB50017 } & $\begin{array}{c}L 1=L 3=L 2 \\
=L\end{array}$ & 0.143 & 0.143 & 0.143 & 0.143 & 0.143 & 0.143 & 0.143 & 0.143 & 0.143 \\
\hline & $\begin{array}{c}L 1=L 3= \\
1.5 L 2=1.5 L\end{array}$ & 0.177 & 0.177 & 0.177 & 0.177 & 0.177 & 0.177 & 0.177 & 0.177 & 0.177 \\
\hline \multirow{2}{*}{ AISC360 } & $\begin{array}{c}L 1=L 3=L 2 \\
=L\end{array}$ & 0.25 & 0.25 & 0.25 & 0.25 & 0.2 & 0.167 & 0.125 & 0.1 & 0.083 \\
\hline & $\begin{array}{c}L 1=L 3= \\
1.5 L 2=1.5 L\end{array}$ & 0.375 & 0.375 & 0.333 & 0.25 & 0.2 & 0.167 & 0.125 & 0.1 & 0.083 \\
\hline
\end{tabular}

Note: $b_{\mathrm{e}}$ is the effective width of the solid concrete slab, and for EN 1994-1-1, it is $b_{\text {eff. }} S_{0}$ is the actual width of the solid concrete slab and equals the distance to the centerline of the adjacent beam; $L$ is the beam span; for mid-span calculation, $L 1=L 2=L 3=L$ in Figure 6 , and for end-span $=1.5$. Mid calculation, $L 1=L 3=1.5 \mathrm{~L} 2=1.5 \mathrm{~L}$ in Figure 6 , and $b_{0}$ is the distance between the centers of the outstand shear connectors.

In summary, there are specific differences in introductory provisions and numerical calculations among the four design specifications. Significantly, the numerical differences are significantly large. For example, using the same steel beam, the same solid concrete slab, and the same shear connector is likely to design different composite joint specimens with varying widths of flange slab.

\section{Design Suggestions of the Slab Width of Composite Joint Specimens}

Because the concrete slab has a critical effect on the fracture failure of the lower flange of the composite joint in SMRFs, researchers hope to quickly and accurately design the slab width of a composite joint specimen, and they have also done ongoing research work.

\subsection{Review of Previous Studies on the Effective Slab Width of Composite Joints}

Although many studies have been done on steel-concrete composite joints, only a little attention has been paid to studying the effective width of slabs in composite joints $[6-11,19,29,30]$. Some researchers believe that the width of the column flange is a critical factor in the effective width. Du Plessis and Daniels [7] suggested the effective width is taken as 1.3 times the width of the column flange. However, a specimen subjected to reversed cyclic loads did not reach the estimated moment capacity based on this assumption [8]. Tagawa et al. [30] considered a compressive force in the concrete slab at the beam 
end in positive bending should be balanced by the bearing stress of concrete at the column face and proposed the effective width of 1.8 times the width of the column flange for the case of H-shaped columns. Chen and Chao [10] observed that the effective width of the concrete slab became smaller, approaching the beam-to-column connection, and the effective width decreased with the increase of loading. The effective width gradually decreased and converged when the specimen was loaded into the inelastic range. They suggested the effective width should be determined by the column flange width and the concrete strength. They also noted that in the current design specifications mentioned above, the concrete strength is not considered to determine the effective width of the slab. Civjan S.A. et al. [29] thought the effective width of the concrete slab depends both on the column flange width and on the column depth. Further, the effective width of the concrete slab appeared to be substantially less than 1.3 times the width of the column flange when subjected to reversed loading. Uang et al. [9] observed that under positive bending, the portion of a concrete slab that was effective in developing compressive stresses were primarily confined in the width of column flange due to direct bearing between the column flange and the concrete slab. Except for a small amount of inclined compression strut action that occurred just outside the column flange width, compressive stresses elsewhere were very low due to the presence of a broad, transverse concrete crack on the other side of the column, where the beam was in negative bending. Nakashima M. et al. [11] conducted an experimental study on a steel moment frame with reinforced concrete RC floor slab subjected to horizontal cyclic loading that led to extensive deformations. Nie and Tao [19] studied the effective width of the concrete slab for ultimate loading capacity in the composite frame. The ultimate effective flange width under the hogging moment at the beam end of the side joint mainly depends on the column width and height, steel beam height, RC slab width, and transverse beam flange width. The main factors influencing the ultimate positive effective flange width include the column width, the steel beam height, and the steel beam flange width. In general, there has been no consensus among researchers on the effective width of the concrete slab in composite joints.

\subsection{Recommend Slab Width for Composite Joint Specimens}

Since researchers have not reached a consensus on the effective slab width for the composite joint, it was best to design a model following the current design specifications. As researchers, they are interested in the proportional relationship between the effective width and the actual width of the slab so that they can quickly design composite joint specimens based on the prototype structure. Thus, this paper also gives $b_{\mathrm{e}} / S_{0}$ for different specifications under different $S_{0} / L$ values. The ratios of the positive and negative bending moment regions appear in Figures 7 and 8, respectively. 


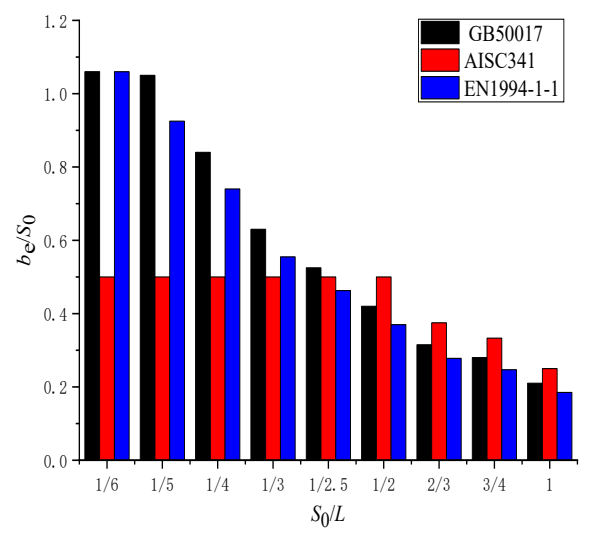

(a)

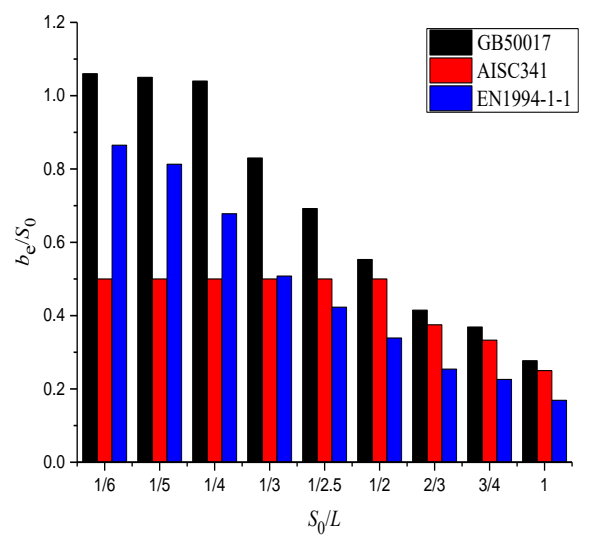

(b)

Figure 7. Comparison of effective flange width ratios $\left(b_{e} / S_{0}\right)$ in the positive bending moment region. (a) At mid-span; (b) at end support.

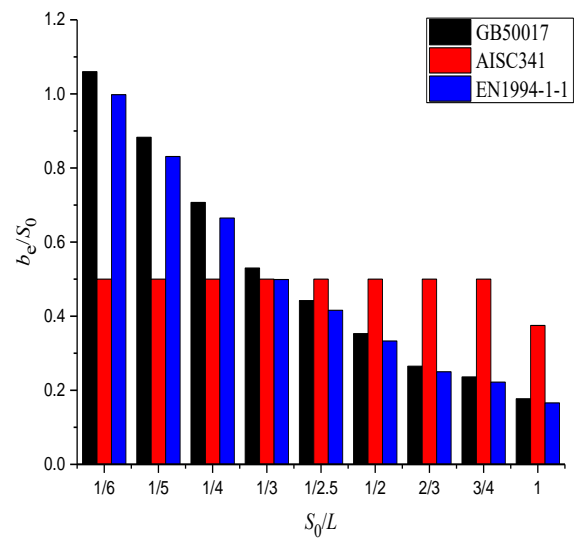

(a)

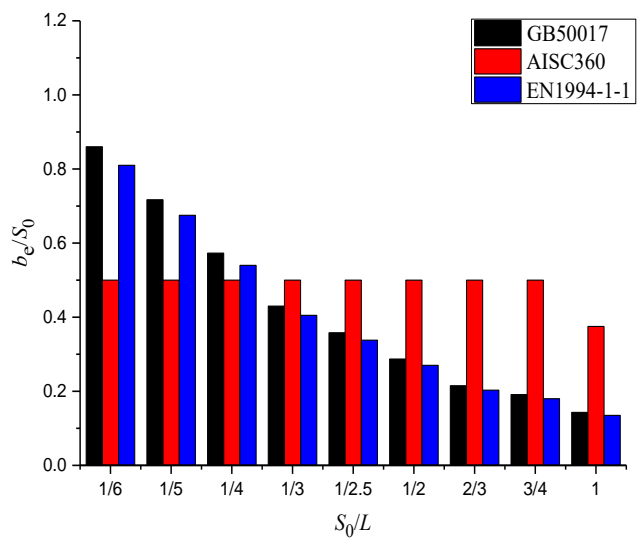

(b)

Figure 8. Comparison of effective flange width ratios $\left(b_{e} / S_{0}\right)$ in the negative bending moment region. (a) $L 1=L 3=L 2=L ;($ b) $L 1=L 3=1.5 L 2=1.5 L$.

It can be seen in Figures 7 and 8 that EN 1994-1-1, specifically GB50017, have calculated ratios greater than 1.0 under certain conditions. Under the condition that beams are continuous and have equal spacing, the ratio calculated by EN 1994-1-1 and GB50017 is always greater than AISC 360 when $S_{0} / L$ is less than $1 / 3$. When $S_{0} / L$ is greater than $1 / 2$, almost all the calculating values of $b_{\mathrm{e}} / S_{0}$ of three specifications are less than 0.5 .

The aim of our research was to avoid the brittle fracture of the bottom beam flange in the joint zone. The effective slab width under the sagging bending state is the most critical factor. However, most researchers mainly focus on seismic performance for composite joints, and cyclic or repeated loadings are commonly used in tests. So, the specimen slab width may be designed according to the effective width of the slab in the composite beam sagging and hogging bending region of the prototype frame. To facilitate the researchers quick and safe designs of composite joint specimens, the recommended value $b_{\mathrm{s}}$, which is the width of the solid concrete slab used in the composite joint, is given based on the numerical calculation results mentioned above.

$$
b_{s}=a S_{0}
$$

where $S_{0}$ is the actual width of the solid concrete slab and equals the distance to the centerline of the adjacent beam in the prototype frame; $L$ is the beam span, center to center of the supports in the prototype frame, and where $\alpha=1$, if $S_{0} / L \leq 0.25 ; \alpha=0.5$, if $S_{0} / L \geq 0.5$; if $0.25<S_{0} / L<0.5$, then $\alpha$ is obtained by linear interpolation. 
Like this article's research purpose, T. Salama and H.H. Nassif recommend Equation (8) to calculate a composite steel beam at the ultimate state [21].

$$
b_{\mathrm{e}}=\left[1-0.25\left(b_{\mathrm{s}} / L\right)\right] b_{\mathrm{s}} \text { for } b_{\mathrm{s}} / L>0.25
$$

where $b_{\mathrm{e}}$ is the effective width of the concrete flange of a composite beam; $b_{\mathrm{s}}$ is the width of the concrete flange of the composite beam and is the same as $S_{0}$ in this paper, $L$ is the same as the definition in this paper, and where $b_{\mathrm{e}}=b_{\mathrm{s}}$ for $b_{\mathrm{s}} / L \leq 0.25$ is the same as in this paper. Moreover, it is found through a calculation that when $b_{\mathrm{s}} / L \geq 0.286$, calculation values of Equation (8) are always greater than Equation (7), and when $0.25<b_{\mathrm{s}} / L<0.286$, calculation values of Equation (8) are always less than Equation (7).

In this paper, the aim of proposing a recommended equation is to give the upper limit of the effective width corresponding to the ratio $S_{0} / \mathrm{L}$ (or $b_{\mathrm{s}} / \mathrm{L}$ in Equation (8)). It can help researchers to design composite joint specimens that meet design specifications quickly. Therefore, the reliability of Equations (7) and (8) had to be verified.

Equation (7) is proposed based on conservative and safe design principles because the effective width of the slab in SMRFs is always smaller than its actual width. The proposed formula gives the upper limit of the effective width corresponding to the ratio between the secondary beam distance and the column spacing. Thus, it can allow researchers to design composite joint specimens that meet design specifications quickly.

\section{Example of Verification of Recommended Equations \\ 6.1. The Composite Joints of SMRFs}

For verifying the reliability of Equations (7) and (8), the authors of this paper designed an FEM calculation example of the composite joint of an SMRF according to an actual project [31,32]. Through analysis using ABAQUS software, the slab's effective width in the composite joint calculation example was obtained and then compared with the value of the FEM model suggested by Equations (7) and (8).

\subsection{The Details of the Base Model of a Composite Joint in the Actual Project}

We selected a real composite joint as the base model from a real SMRF in the standard industrial park project, as reported by the author in 2018 [31]. The column space of the prototype SMRF was $7800 \mathrm{~mm}$ in two directions in the plane, the story height was $3600 \mathrm{~mm}$, and the actual width of the solid concrete slab $S_{0}$ was $1950 \mathrm{~mm}$. The finite element analysis of similar composite joints was also reported by the author in 2019 [32]. There are two differences between the model in this paper and that in the reference [32]; the composite joint has two transverse beams and different concrete slab sizes- the details of the composite joint is shown in Figure 9. The substructure was fabricated using Grade Q345 steel with a specified minimum yield strength of $345 \mathrm{MPa}$ and Grade C 30 concrete and consisted of an $\mathrm{H} 500 \times 500 \times 16 \times 24$ column (height: $3600 \mathrm{~mm}$ ), two $\mathrm{H} 600 \times 200 \times 10 \times 16$ beams (span: $3900 \mathrm{~mm}$ ), and a $7800 \times 1950 \times 100$ (length $\times$ width $\times$ thickness) slab. The shear head studs $16 \mathrm{~mm}$ in diameter and $80 \mathrm{~mm}$ long with $100 \mathrm{~mm}$ intervals were set in a double row in beam top flanges to achieve full composite action between the slab and steel beam. The actual yield strength, ultimate tensile strength, elastic modulus, and elongation of Grade Q345 steel are 333.33 Mpa, $458.33 \mathrm{Mpa}, 2.06 \times 10^{5} \mathrm{Mpa}$, and 21.9\%, respectively [32]. In addition, the actual yield strength, ultimate tensile strength, elastic modulus, and HRB 400 reinforcement elongation are $419 \mathrm{Mpa}, 577 \mathrm{Mpa}, 2.0 \times 10^{5} \mathrm{Mpa}$, and 32\%, respectively [33]. Therefore, the actual yield strength, ultimate tensile strength, and elongation for the head studs are $240 \mathrm{Mpa}, 490 \mathrm{Mpa}$, and 15\%, respectively. The actual yield and maximum tensile strength of high-strength bolts are $940 \mathrm{Mpa}$ and $1130 \mathrm{Mpa}$, respectively [34]. According to the lab test results, the concrete's compression strength, tension strength, elastic modulus, and Poisson ratio are $20.1 \mathrm{Mpa}, 2.01 \mathrm{Mpa}, 2.11 \times 10^{4} \mathrm{Mpa}$, and 0.2, respectively. 


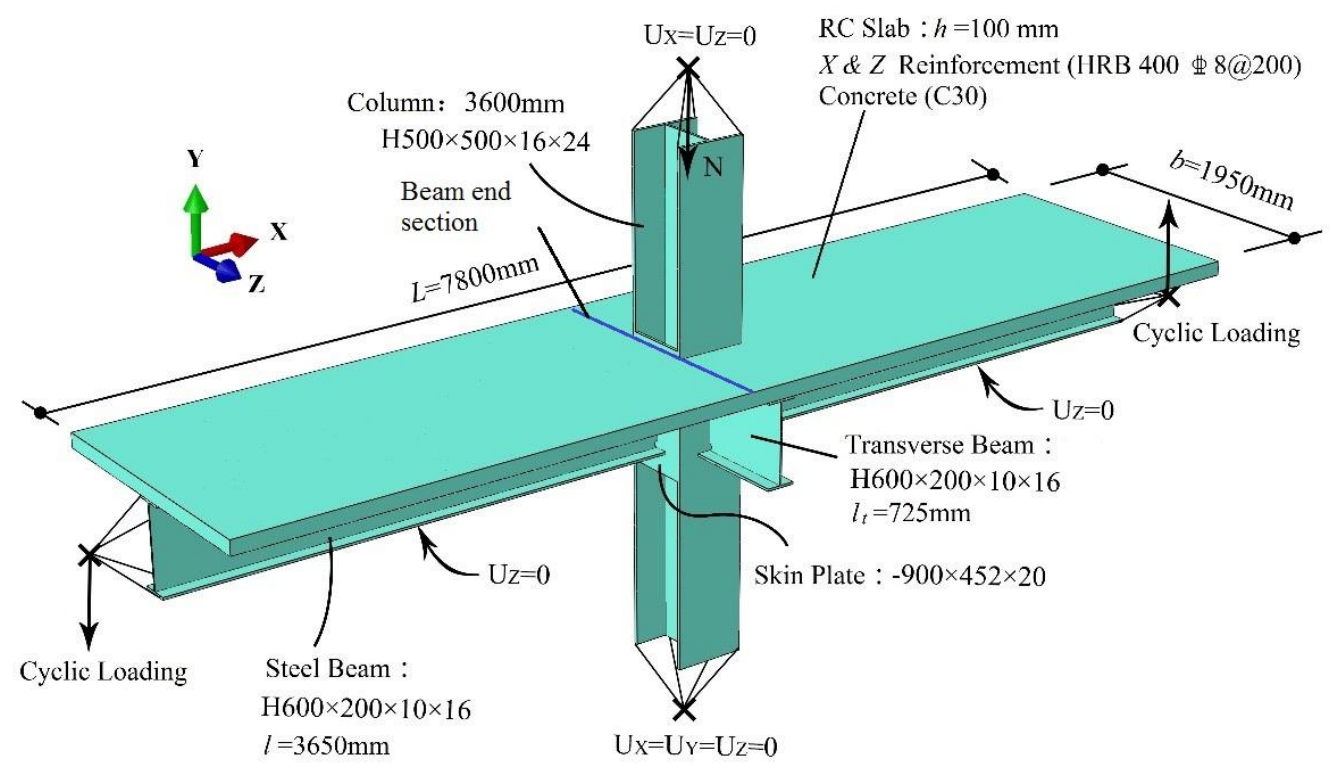

Figure 9. Details of the base composite joint in the ABAQUS analysis.

In the steel frame of the actual project, the composite floor slab and the steel beam (steel beam and transverse beam in Figure 9) are connected by welded studs. According to EN 1994-1-1, the composite slab shown in Figure 9 belongs to the composite slab with end anchorage. For the research for this paper, the stress of the beam end section at the solid blue line in Figure 9 was extracted, and we adopted the beam free-end loading method. As such, the FE model of the cross-shaped composite joint shown in Figure 9 is entirely consistent with the force mechanism of the side frame T-shaped composite joint, in which the composite beam ends in its joint with the column. Therefore, the conclusion obtained from the cross-shaped composite joint is also fully applicable to the T-shaped composite joint.

\subsection{FEM Analysis Method}

We used the same 3-D FEM analysis ABAQUS method in this study as the method of reference [32], including the element type (steel, reinforcements, and concrete), mesh division, boundary processing, and AISC cyclic seismic loading protocol, and more.

\subsection{Ultimate State and the Calculation Method of Effective Slab Width}

In the literature on the effective slab width of the composite beam, some scholars believe that the ultimate strength state of composite beams needs to be considered $[19,21,35]$. Therefore, we considered two kinds of ultimate states in the ABAQUS analysis. One was the story-drift angle (the loading rotation angle in the beam end) that equals $0.02 \mathrm{rad}$, as required by the seismic design code of China [36]; the other was the story-drift angle that equals $0.04 \mathrm{rad}$, according to ANSI/AISC 341-16 [25]. The calculation method for the effective slab width was the same as the one used by Amadio and Fragiacomo [37]. In the sagging bending moment region, the effective slab width for the base composite joint was $473 \mathrm{~mm}$ and $500 \mathrm{~mm}$ under $0.02 \mathrm{rad}$ and $0.04 \mathrm{rad}$ ultimate states, respectively. In the hogging bending moment region, the effective slab width was $1170 \mathrm{~mm}$ and $1414 \mathrm{~mm}$, separately. Therefore, we selected the 0.04 rad beam end rotation as the loading ultimate in the following analysis.

\subsection{ABAQUS Analysis Results and Comparison}

Regarding the base composite joint, and considering the common column space of SMRFs, there were a total of nine specimens used in the ABAQUS analysis by changing the beam length $L$ (see Table 4 ) or by changing the $S_{0}$ (see Table 5). The ABAQUS analysis data and the calculation results of Equations (7) and (8) are listed in Tables 4 and 5. 
Civjan et al. [29] reported that the concrete slab's effective width appeared to be substantially less than 1.3 times the width of the column flange when subjected to reversed loading; the effective width was approximately equal to the column flange width. In Tables 4 and 5 , the $b_{\mathrm{e}}$ of ABAQUS under sagging bending is from 0.924 times $(462 \mathrm{~mm})$ to 1.134 times $(567 \mathrm{~mm})$ that of the column width $(500 \mathrm{~mm})$. These results show that the ABAQUS analysis in this paper is entirely accurate. These results also show that the effective width under the sagging bending moment is less affected by the $S_{0}$ and maintains a constant within a specific range. Compared to the smaller effective width under the sagging bending moment, the effective width under the hogging bending moment is larger than the column width. The effective width under the hogging bending moment is greatly affected by the $S_{0}$ and increases with the increase of $S_{0}$.

Table 4. The effective slab width under changing $L$.

\begin{tabular}{|c|c|c|c|c|c|c|c|c|c|c|}
\hline \multirow[t]{2}{*}{ Specimen } & $\begin{array}{l}L=72 \\
S_{0}=1\end{array}$ & $00 \mathrm{~mm}$ & $\begin{array}{l}L=78 \\
S_{0}=1\end{array}$ & $\begin{array}{l}00 \mathrm{~mm} \\
50 \mathrm{~mm}\end{array}$ & $\begin{array}{r}\text { Design } \\
L=84 \\
S_{0}=1\end{array}$ & $\begin{array}{l}\text { Conditions } \\
0 \mathrm{~mm} \\
50 \mathrm{~mm}\end{array}$ & $\begin{array}{l}L=96 \\
S_{0}=1\end{array}$ & $\begin{array}{l}0 \mathrm{~mm} \\
0 \mathrm{~mm}\end{array}$ & $\begin{array}{c}L=10 \\
S_{0}=1\end{array}$ & $\begin{array}{l}00 \mathrm{~mm} \\
50 \mathrm{~mm}\end{array}$ \\
\hline & Sagging & Hogging & Sagging & Hogging & Sagging & Hogging & Sagging & Hogging & Sagging & Hogging \\
\hline $\begin{array}{l}\text { ABAQUS: } \\
b_{\mathrm{e}} / \mathrm{mm}\end{array}$ & 488 & 1407 & 500 & 1414 & 520 & 1423 & 529 & 1485 & 528 & 1490 \\
\hline $\begin{array}{c}\text { Equation (7): } \\
b_{\mathrm{s}} / \mathrm{mm}\end{array}$ & \multicolumn{2}{|c|}{1869} & \multicolumn{2}{|c|}{1950} & \multicolumn{2}{|c|}{1950} & \multicolumn{2}{|c|}{1950} & \multicolumn{2}{|c|}{1950} \\
\hline $\begin{array}{c}\text { Equation (8): } \\
b_{\mathrm{e}} / \mathrm{mm}\end{array}$ & \multicolumn{2}{|c|}{1818} & \multicolumn{2}{|c|}{1950} & \multicolumn{2}{|c|}{1950} & \multicolumn{2}{|c|}{1950} & \multicolumn{2}{|c|}{1950} \\
\hline
\end{tabular}

Table 5. The effective slab width under changing $S_{0}$.

\begin{tabular}{|c|c|c|c|c|c|c|c|c|c|c|}
\hline \multirow[t]{2}{*}{ Specimen } & \multicolumn{6}{|c|}{$\begin{array}{c}\text { Design Conditions } \\
L=7800 \mathrm{~mm} \\
S_{0}=1950 \mathrm{~mm}\end{array}$} & \multicolumn{2}{|c|}{$\begin{array}{c}L=7800 \mathrm{~mm} \\
S_{0}=2500 \mathrm{~mm}\end{array}$} & \multicolumn{2}{|c|}{$\begin{array}{c}L=7800 \mathrm{~mm} \\
S_{0}=3000 \mathrm{~mm}\end{array}$} \\
\hline & Sagging & Hogging & Sagging & Hogging & Sagging & Hogging & Sagging & Hogging & Sagging & Hogging \\
\hline $\begin{array}{c}\text { ABAQUS } \\
b_{\mathrm{e}} / \mathrm{mm}\end{array}$ & 462 & 707 & 473 & 1064 & 500 & 1414 & 553 & 1658 & 567 & 1949 \\
\hline $\begin{array}{l}\text { Equation (7) } \\
b_{\mathrm{s}} / \mathrm{mm}\end{array}$ & \multicolumn{2}{|c|}{1000} & \multicolumn{2}{|c|}{1500} & \multicolumn{2}{|c|}{1950} & \multicolumn{2}{|c|}{2147} & \multicolumn{2}{|c|}{2192} \\
\hline $\begin{array}{l}\text { Equation (8): } \\
b_{\mathrm{e}} / \mathrm{mm}\end{array}$ & \multicolumn{2}{|c|}{1000} & \multicolumn{2}{|c|}{1500} & \multicolumn{2}{|c|}{1950} & \multicolumn{2}{|c|}{2300} & \multicolumn{2}{|c|}{2712} \\
\hline
\end{tabular}

The data in Tables 4 and 5 show that the calculation results of Equations (7) and (8) are very inclusive and completely cover the effective width of the slab obtained by the ABAQUS analysis. However, compared to the calculation results of Equation (8), the calculation results of Equation (7) are closer to the ABAQUS analysis results. Therefore, it is feasible and safe to design composite joint specimens according to Equation (7) for experimental research.

\subsection{The Influence of Slab Thickness on the Effective Width}

The slab's effective width given by the current design specifications $[12,13,24,26]$ has nothing to do with the thickness of the slab. However, the last version of the Chinese design code GB 50017-2003 [38] included a clause related to the effective width and thickness of the slab, requiring that the slab's effective width cannot exceed 12 times the thickness of the slab. The author of this paper has designed the experiment's composite joint specimens [33] according to this clause [38]. Therefore, the slab thickness $\left(h_{c}\right)$ in relation to the slab's effective width was still analyzed for this paper. The specimens' details are the same as the base model $\left(L=7800 \mathrm{~mm}, S_{0}=1950 \mathrm{~mm}\right.$, and $\left.h_{\mathrm{c}}=100 \mathrm{~mm}\right)$ except for the slab thickness. The ABAQUS analysis data and the calculation results of Equations (7) and (8) are listed in Table 6. 
Table 6. The effective slab width under changing slab thickness $h_{\mathrm{c}}$.

\begin{tabular}{|c|c|c|c|c|c|c|c|c|}
\hline \multirow{5}{*}{ Specimen } & \multicolumn{8}{|c|}{ Design conditions } \\
\hline & \multirow{3}{*}{\multicolumn{2}{|c|}{$\begin{array}{c}L=7800 \mathrm{~mm} \\
S_{0}=1950 \mathrm{~mm} \\
h_{\mathrm{c}}=100 \mathrm{~mm}\end{array}$}} & \multirow{3}{*}{\multicolumn{2}{|c|}{$\begin{array}{c}L=7800 \mathrm{~mm} \\
S_{0}=1950 \mathrm{~mm} \\
h_{\mathrm{c}}=120 \mathrm{~mm}\end{array}$}} & \multirow{3}{*}{\multicolumn{2}{|c|}{$\begin{array}{c}L=7800 \mathrm{~mm} \\
S_{0}=1950 \mathrm{~mm} \\
h_{\mathrm{c}}=150 \mathrm{~mm}\end{array}$}} & \multirow{3}{*}{\multicolumn{2}{|c|}{$\begin{array}{c}L=7800 \mathrm{~mm} \\
S_{0}=1950 \mathrm{~mm} \\
h_{\mathrm{c}}=180 \mathrm{~mm}\end{array}$}} \\
\hline & & & & & & & & \\
\hline & & & & & & & & \\
\hline & Sagging & Hogging & Sagging & Hogging & Sagging & Hogging & Sagging & Hogging \\
\hline $\begin{array}{l}\text { ABAQUS: } \\
b_{\mathrm{e}} / \mathrm{mm}\end{array}$ & 500 & 1414 & 481 & 1395 & 466 & 1335 & 464 & 1334 \\
\hline $\begin{array}{l}\text { Equation (7): } \\
\qquad b_{\mathrm{s}} / \mathrm{mm}\end{array}$ & \multicolumn{2}{|c|}{1869} & \multicolumn{2}{|c|}{1950} & \multicolumn{2}{|c|}{1950} & \multicolumn{2}{|c|}{1950} \\
\hline $\begin{array}{c}\text { Equation (8): } \\
b_{\mathrm{e}} / \mathrm{mm}\end{array}$ & \multicolumn{2}{|c|}{1818} & \multicolumn{2}{|c|}{1950} & \multicolumn{2}{|c|}{1950} & \multicolumn{2}{|c|}{1950} \\
\hline
\end{tabular}

In Table 6 , the $b_{\mathrm{e}}$ of ABAQUS under sagging bending is from 0.928 times $(464 \mathrm{~mm})$ to 1.0 times $(500 \mathrm{~mm})$ that of the column width $(500 \mathrm{~mm})$. These ABAQUS finite element analysis results still maintain good consistency with the conclusions of Civjan et al. [29]. The data in Table 6 show that the calculation results of Equations (7) and (8) are very inclusive and completely cover the analysis results obtained by ABAQUS. Furthermore, the calculation results of Equation (7) are the same as those of Equation (8) because Equations (7) and (8) all do not consider the influence of slab thickness. Thus, the data in Table 6 reflect an objective fact-as the slab's thickness increases, the effective width decreases. However, the data in Table 6 also reflect that the influence of slab thickness is between $-5.7 \%$ and $-7.2 \%$, indicating that the impact of slab thickness on the effective width is not very large, and Equation (7) in the text is sufficient to cover the effect of slab thickness.

\section{Conclusions}

Since researchers have no consensus on the concrete slab's effective width in composite joints, the best way to design a specimen is to follow the current design specifications. As such, the authors of this paper compared the effective flange width provisions of several countries, China, the United States, Australia,/New Zealand, and the European Union.

1. Each specification has the same organization describing the effective flange widthbasic formulation plus equivalent span length—and they are more or less the same in these two aspects;

2. In the sagging moment region, compared to the Eurocode and Oceanian specifications and the Chinese specifications, ANSI/AISC 360 underestimates the slab's effective width value within the general SMRF size range $\left(S_{0} / L \leq 0.5\right)$. In contrast, in all specifications, the latest version of GB 50,017 in China is the most conservative for the slab's effective width within the general SMRF size range $\left(S_{0} / L \leq 0.5\right)$;

3. For the composite beam hogging moment region, in the range of $S_{0} / L>0.5$, the U.S. specifications control the slab's effective width;

4. The calculation results of Equation (7) are very inclusive and completely cover the slab's effective width obtained by the ABAQUS analysis. Therefore, Equation (7) is feasible and safe to design composite joint specimens of SMRFs for experimental research.

Author Contributions: Conceptualization, L.L. and D.W.; software, K.D.; validation, L.L., K.D., and H.Y.; resources, D.W.; writing-original draft preparation, L.L.; writing-review and editing, L.L., K.D., H.Y., and H.H.; project administration, D.W.; funding acquisition, D.W. All authors have read and agreed to the published version of the manuscript.

Funding: This research was funded by the Nature Science Foundation of China (NSFC) (51278061) and the Fundamental Research Funds for the Central Universities Cultivation of Chang'an University (300102288201).

Institutional Review Board Statement: Not applicable.

Informed Consent Statement: Not applicable. 


\section{Data Availability Statement: Not applicable.}

Acknowledgments: Thanks to China Construction Third Bureau Group Co., Ltd. for its financial support for the project.

Conflicts of Interest: The authors declare no conflict of interest.

\section{References}

1. de Leon, D.; Reyes, A.; Yu, C. Probabilistic assessment of connections for steel buildings on seismic zones. J. Constr. Steel Res. 2013, 88, 15-20. [CrossRef]

2. Memari, M.; Mahmoud, H. Performance of steel moment resisting frames with RBS connections under fire loading. Eng. Struct. 2014, 75, 126-138. [CrossRef]

3. Morshedi, M.A.; Dolatshahi, K.M.; Maleki, S. Double reduced beam section connection. J. Constr. Steel Res. 2017, 138, 283-297. [CrossRef]

4. Kim, Y.J.; Oh, S.H.; Moon, T.S. Seismic behavior and retrofit of steel moment connections considering slab effects. Eng. Struct. 2004, 26, 1993-2005. [CrossRef]

5. Bursi, O.S.; Gramola, G. Behavior of composite substructures with full and partial shear connection under quasi-static cyclic and pseudo-dynamic displacements. Mater. Struct. 2000, 33, 154-163. [CrossRef]

6. Bursi, O.S.; Sun, F.F.; Postal, S. Non-linear analysis of steel-concrete composite frames with full and partial shear connection subjected to seismic loads. J. Constr. Steel Res. 2005, 61, 67-92. [CrossRef]

7. Du Plessis, D.P.; Daniels, J.H. Strength of Composite Beam to Column Connections; Fritz Laboratory Reports; Lehigh University: Bethlehem, PA, USA, 1973.

8. Lee, S.J.; Lu, L.W. Cyclic tests of full-scale composite joint subassemblages. J. Struct. Eng. 1989, 115, 1977-1998. [CrossRef]

9. Uang, C.M.; Yu Kent, Q.S.; Noel, S.; Gross, J. Cyclic testing of steel moment connections rehabilitated with RBS or welded haunch. J. Struct. Eng. 2000, 126, 57-68. [CrossRef]

10. Chen, S.J.; Chao, Y.C. Effect of composite action on seismic performance of steel moment connections with reduced beam sections. J. Constr. Steel Res. 2011, 57, 417-434. [CrossRef]

11. Nakashima, M.; Matsumiya, T.; Suita, K.; Zhou, F. Full-scale test of composite frame under large cyclic loading. J. Struct. Eng. 2007, 133, 297-304. [CrossRef]

12. EN 1994-1-1:2004. Eurocode 4: Design of Composite Steel and Concrete Structures Part 1-1: General Rules and Rules for Buildings (Incorporating Corrigendum April 2009); The European Union Per Regulation: Brussels, Belgium, 2009.

13. AS/NZS 2327:2017. Composite Structures—Composite Steel-Concrete Construction in Buildings; Joint Technical Committee BD-032, Composite Construction: Sydney, Australia, 2017.

14. Sedlacek, G.; Bild, S. Simplified method for the determination of the effective width due to shear lag effects. J. Constr. Steel Res. 1993, 24, 155-182. [CrossRef]

15. Dezi, L.; Gara, F.; Leoni, G.; Tarantino, A.M. Time-dependent analysis of shear-lag effect in composite beams. J. Eng. Mech. 2001, 127, 71-79. [CrossRef]

16. Ayensa, A.; Oller, E.; Beltrán, B.; Ibarz, E.; Marí, A.; Gracia, L. Influence of the flanges width and thickness on the shear strength of reinforced concrete beams with T-shaped cross section. Eng. Struct. 2019, 188, 506-518. [CrossRef]

17. Khalil, A.E.; Etman, E.; Atta, A.; Baraghith, A.; Behiry, R. The Effective Width in Shear Design of Wide-shallow Beams: A Comparative Study. KSCE J. Civ. Eng. 2019, 23, 1670-1681. [CrossRef]

18. Ahn, I.S.; Chiewanichakorn, M.; Chen, S.S.; Aref, A.J. Effective flange width provisions for composite steel bridges. Eng. Struct. 2004, 26, 1843-1851. [CrossRef]

19. Nie, J.G.; Tao, M.X. Slab spatial composite effect in composite frame systems. I: Effective width for ultimate loading capacity. Eng. Struct. 2012, 38, 171-184. [CrossRef]

20. Lasheen, M.; Shaat, A.; Khalil, A. Numerical evaluation for the effective slab width of steel-concrete composite beams. J. Constr. Steel Res. 2018, 148, 124-137. [CrossRef]

21. Salama, T.; Nassif, H.H. Effective Flange Width for Composite Steel Beams. The J. Eng. Res. 2011, 8, 28-43. [CrossRef]

22. Mohsen, M.H.; Mohammed, S.N. The Effective Width in Composite Steel Concrete Beams at Ultimate Loads. J. Eng. 2014, 20, 1-17.

23. Alsarraf, M.A.A.; EI Din, H.S. Effects of Web Openings on the Effective Slab Widths in Composite Steel Beams. Int. J. Eng. Technol. 2016, 8, 6-10. [CrossRef]

24. GB50017-2017. Standard for Design of Steel Structures; China Plan Press: Beijing, China, 2017.

25. ANSI/AISC 341-16. Seismic Provisions for Structural Steel Buildings (Revised June 2018); American Institute of Steel Construction: Chicago, IL, USA, 2018.

26. ANSI/AISC 360-16. Specification for Structural Steel Buildings (Revised June 2019); American Institute of Steel Construction: Chicago, IL, USA, 2019.

27. AISC-LRFD. Load and Resistance Factor Design Specification for Structural Steel Buildings; American Institute of Steel Construction: Chicago, IL, USA, 1999. 
28. Amadio, C.; Fedrigo, C.; Fragiacomo, M.; Macorini, L. Experimental evaluation of effective width in steel-concrete composite beams. J. Constr. Steel Res. 2004, 60, 199-220. [CrossRef]

29. Civjan, S.A.; Engelhard, M.D.; Gross, J.L. Slab effects in SMRF retrofit connection tests. J. Struct. Eng. 2001, 127, 230-237. [CrossRef]

30. Tagawa, Y.; Kato, B.; Aoki, H. Behavior of composite beams in steel frame under hysteretic loading. J. Struct. Eng. 1989, 115, 2029-2045. [CrossRef]

31. Lu, L.F.; Xu, Y.L.; Zheng, H.X.; Lim, J.B.P. Cyclic response and design procedure of a weak-axis cover-plate moment connection. Steel Compos. Struct. 2018, 26, 139-150.

32. Xu, Y.L.; Lu, L.F.; Zheng, H. Finite element analysis of weak-axis composite connections under cyclic loading. Int. J. Steel Struct. 2019, 19, 82-95. [CrossRef]

33. Lu, L.F.; Xu, Y.L.; Zheng, H. Investigation of composite action on seismic performance of weak-axis column bending connections. J. Constr. Steel Res. 2017, 129, 286-300. [CrossRef]

34. Lu, L.F.; Xu, Y.L.; Lim, J.B.P. Mechanical performance of a new I-section weak-axis column bending connection. Steel Compos. Struct. 2018, 26, 31-44.

35. Nie, J.G.; Tian, Y.; Cai, C.S. Effective width of steel-concrete composite beam at ultimate strength state. Eng. Struct. 2008, 30, 1396-1407. [CrossRef]

36. GB50011-2010. Code for Seismic Design of Buildings; China Architecture and Building Press: Beijing, China, 2010.

37. Amadio, C.; Fragiacomo, M. Effective width evaluation for steel-concrete composite beams. J. Constr. Steel Res. 2002, 58, 373-388. [CrossRef]

38. GB 50017-2003. Code for Design of Steel Structure; China Plan Press: Beijing, China, 2003. 